\title{
Rechtsgeschichte
}

http://www.rg-rechtsgeschichte.de/rg4

$\operatorname{Rg} 2004$

$84-113$

Zitiervorschlag: Rechtsgeschichte Rg 4 (2004)

http://dx.doi.org/10.12946/rg04/084-113

\section{Dieter Simon}

\section{Zeithorizonte}

Versuch über verschwendetes Leben 


\section{Abstract}

No research is without intellectual content. It always carries traces of provenance with it around. Sometimes it appears that knowledge comes too late. The train is gone or the gloves are delivered while summer is already beginning. Then all sacrifices were in vain and those who renounced their lives find no comfort. When a language is not spoken anymore and its witnesses are gathering dust in the closets, it is unsuitable to let life fade away over a dictionary. Yet futility deserves a commemorative plaque. Such will be attempted by this text for the $\mathrm{V}$ (ocabularium) I(urisprudentiae) $\mathrm{R}$ (omanae). This is why it could also be titled: Short history of VIR. 


\section{Zeithorizonte*}

Versuch über verschwendetes Leben

"Ein jegliches hat seine Zeit und alles Vornehmen unter dem Himmel hat seine Stunde". Wir wissen das. Wir wussten es vermutlich schon lange bevor der »Prediger "Salomo (3.I), der ein Philosoph war, uns vor nunmehr gut 2200 Jahren darüber belehrte. Aber wir handeln nur selten nach unseren Einsichten. Trennungen fallen schwer und Gewohnheiten verkleiden sich bereitwillig als Notwendigkeit. Verschwendung ist den Reichen keine Kategorie, und wer vom Verschwender lebt, erhebt keine Vorwürfe. Schließlich das Wichtigste: Wer außer Gott hat Kraft und Befugnis »Zeit « und »Stunde « zu bestimmen?

Wir bedienen uns hier der frechen Metapher "Zeithorizont «, um dem Unbegrenzten und Unbegrenzbaren eine visuelle Trennungslinie einzuziehen, eine Gesichtskreisstütze und Sehfeldanregung, mit deren Hilfe man die ozeanische Zeit verdicken, in Stücke schneiden und verpacken kann.

Rechtsgeschichtsschreibung, die dazu neigt, die gebotene stille Beobachtung der Wirkung des Normativen mit der energischen Normierung des vermeintlich Beobachteten zu vermischen, findet im Zeithorizont ein probates Mittel zur Konstruktion von Orientierungen.

Herausgegriffen aus der unendlichen Fülle der Möglichkeiten, die das wissenschaftliche »Vornehmen « bietet, folgen fünf Lebensläufe, zurechtgestutzt, moduliert und portioniert mit Hilfe von Horizonten, die sich am Ende alle zum Prediger Salomo hin öffnen: "Man arbeite, wie man will, so hat man keinen Gewinn davon" (3.9).

I.

Der erste Lebenslauf ist der des römischen Rechts. Das römische Recht ist bekanntlich seit dem I 5 . Jahrhundert in Deutschland aufgetaucht, hat sich rasch aus der Rolle des Gastes befreit und sich zum Lehrmeister und Zuchtmeister gewandelt, um schließlich im I9. Jahrhundert als fast unangefochtener Monarch das Feld der deutschen Rechtskultur zu beherrschen. Rezeption des römischen Rechts nennt man diesen Vorgang.

\footnotetext{
* Überarbeitete und erweiterte Fassung eines im Oktober 2002 in der Berlin-Brandenburgischen Akademie der Wissenschaften unter dem Titel »Ein besonders erfolgreiches Langzeitvorhaben « gehaltenen Vortrags.
} 
Eine Vokabel der Verlegenheit, die allerlei Gründe, Vermutungen, Rationalisierungen und Entschuldigungen zusammenfassen und verstecken muss. Mit ihr wird der merkwürdige und letztlich immer noch unverständliche Sachverhalt beschrieben, dass die Regeln, Prinzipien und Weisungen, mit denen eine moderne Gesellschaft ihre Konflikte bereinigt und ihre Planungen umzäunt, mittels enormer gedanklicher Anstrengung aus Texten gezogen, gepresst und destilliert wurden, die im Kern aus einer fast 2000 Jahre alten, fremdsprachigen, und von der gerade existierenden Welt denkbar verschiedenen Sphäre stammen.

Denn was war dieses römische Recht eigentlich? Keine Sammlung von Normen, wie man es von einem kontinentalen Gesetzeswerk der Gegenwart kennt und erwartet, sondern eine dreiteilige Sammlung von Fällen, mit eingearbeiteten rechtsgelehrten Voten und kaiserlichen Entscheidungen. Die Digesten, der Codex und die Novellen, zusammen bekannt als das so genannte Corpus Iuris Civilis, die Gesamtheit des bürgerlichen Rechts.

Die Digesten: eine riesige Sammlung ehemals strittiger Sachverhalte, überwiegend den Schriften römischer Juristen der ersten zweieinhalb Jahrhunderte nach Christus als Fragmente entnommen, leidlich geordnet in 50 Büchern und 428 Titeln, die als Raster für die Auffindung gesuchter Präjudizien allerdings wenig tauglich sind. Die Fälle werden in äußerster abstrakter Verdichtung geschildert, die darauf bezogenen rechtlichen Erwägungen und Argumentationen haben wegen ihrer sachgebundenen Eleganz und wegen des stupenden Scharfsinns ihrer Autoren über die Jahrhunderte hinweg den an Rechtsstrukturen interessierten abendländischen Verstand tief beeindruckt.

Der Codex: Eine Sammlung kaiserlicher Entscheidungen und Anordnungen vom 3. bis zum 6. Jahrhundert nach Christus. Auch sie, wie eigentlich alle Rechtsnormen bis heute, hervorgegangen aus Erfahrungen mit Konflikten, deren Beilegung dem Gewalthaber angetragen worden war.

Die Novellen: rund I70 umfangreiche legislative Akte, mit geringen Ausnahmen von Kaiser Justinian erlassen, der zwischen 528 und 533 nach Christus die Herstellung von Digesten und Codex angeordnet hatte. Mit seinen Novellen, den »Neuerungen «, unternahm der berühmte byzantinische Kaiser den nur bruchstückhaft gelungenen Versuch, das schon damals alte und veraltete römische Recht den modernen, d. h. seinen Zeiten anzupassen. 
"Es ist besser eine Hand voll mit Ruhe, denn beide Fäuste voll mit Mühe und Haschen nach Wind." (Prediger 4.6)
Diese Masse von Rechtstexten, die planmäßige Kompilation eines byzantinischen Kaisers und seiner beamteten Kanzlisten, war jenes römische Recht, das im Abendland über reichlich 800 Jahre traktiert, interpretiert und reformuliert wurde und - in freilich höchst bescheidener Weise - immer noch wird.

Warum es diesem Korpus einstmals gelang, das ältere deutsche Privatrecht weitgehend zu verdrängen und sich in Rechtslehre, Gesetzgebung und Rechtsanwendung zu nahezu alleiniger Herrschaft aufzuschwingen, das wird wohl auch in Zukunft noch mit einer so oder anders gewichteten Mischung aus den vielzitierten Faktoren »mittelalterliche Reichsidee«, »juristischer Humanismus «, » neue Verkehrsbedürfnisse «, »Staatsentstehung «, »Verwissenschaftlichung des Rechtswesens « usw. bearbeitet und erklärt werden.

Mir kommt es allerdings weniger auf das Aufkommen, den Aufstieg und das Aufblühen des römischen Rechts an, als auf seinen Scheitelpunkt und den folgenden, am Ende raschen Niedergang. Der Scheitelpunkt wurde in Deutschland zweifellos mit Friedrich Carl von Savigny erreicht. Dem I 779 geborenen und I 86I » in höchstem deutschen und europäischen Ruhme« (Wieacker) gestorbenen Frankfurter und seiner historischen Rechtsschule gelang es, in strikter Gegnerschaft zu dem als traditionsfeindlich und unwissenschaftlich eingeschätzten Vernunftrecht des aufklärerischen I8. Jahrhunderts, ein geschichtliches Programm zur Erneuerung der Rechtswissenschaft aus dem Geiste des römischen Rechts zu entwerfen und politisch durchzusetzen.

In der Folge entfaltete sich die nach den »Pandekten ", der griechischen Bezeichnung für die »Digesten «, »Pandektistik « genannte Rechtswissenschaft. Sie führte, nach dem heutigen Urteil der internationalen Rechtshistoriker, die deutsche privatrechtlich dominierte Rechtskultur auf ihren vermutlich höchsten Gipfel. Es war ein Gipfel, der, wie alle Gipfel, nur noch den Abstieg zuließ und bei jeder Form von Fortbewegung auch erzwang.

Die unwahrscheinliche und immer noch zu schreibende Verlaufsgeschichte dieser rechtsliterarischen Bewegung des I9. Jahrhunderts zeitigte eine ganze Reihe höchst erstaunlicher Wirkungen:

Sie brachte es fertig, in romantischer Anknüpfung an einen kulturellen Volksbegriff, das römische Recht als eine organische Erscheinung des deutschen Volkslebens und die gelehrten Juristen 
als exklusive Repräsentanten des postulierten Volksgeistes erscheinen zu lassen.

Sie konstruierte aus der widerspruchsvollen, heterogenen und letztlich wirren Traditionsmasse der römischen Texte durch gezielte Auswahl, Pointierung und Harmonisierung eine für Rechtsschöpfung und Rechtsanwendung gleichermaßen geeignete hochabstrakte romanistische Rechtsdogmatik, in der die »Quellen «, wie die wunderbare und unerschöpfliche Metapher für die Traditionstexte lautet, nicht mehr als hermeneutische Herausforderung, sondern nur noch als konsentierte Bezugspunkte für die freie Entwicklung des schöpferischen Rechtsgedankens fungierten.

Die Pandektistik hat durch ihre dem Historismus verpflichtete Enthüllung der Geschichtlichkeit des Rechts Rechtsgeschichte möglich und sichtbar gemacht, ohne sich selbst so weit auf Geschichte einzulassen, dass ihre rechtspolitischen und rechtstheoretischen Postulate beschädigt worden wären.

Schließlich mobilisierte die Pandektistik eine kräftige, nationalromantisch und rechtspolitisch motivierte, intellektuelle Gegenwehr, die schon um die Mitte des Jahrhunderts Studien über die prinzipiellen Unterschiede zwischen römischem und deutschem Recht sowie über die Vorzüge des letzteren hervortrieb. Im Verlaufe dieser Auseinandersetzungen spalteten sich die rechtshistorisch engagierten Juristen in Romanisten und Germanisten, eine Spaltung, deren Spuren in der Geschichte der juristischen Fakultäten der Bundesrepublik bis auf den heutigen Tag beobachtet werden können.

Drehen wir den Zeithorizont von der Pandektistik nach vorn auf das 20. Jahrhundert, dann erscheint auf der Bühne der allmähliche Niedergang des römischen Rechts und sein endlicher Tod im letzten Viertel des verflossenen Säkulums.

Der erste, heftige und schon tödliche Schlag ging von der erfolgreichen Kodifikationsbewegung aus. Mit dem I. Januar des Jahres I900 trat nach langer, fast 30-jähriger Planungs- und Vorbereitungszeit das Deutsche Bürgerliche Gesetzbuch in Kraft.

Mit ihm erhielt das gesamte römische Recht den Status von Gesetzesmaterialien, die zwar zum Verständnis und zur Auslegung des legislatorischen Willens herangezogen werden konnten, aber nicht mussten. Mochte das neue Gesetzbuch unstrittig vom römischrechtlichen Geist tief imprägniert sein - die alten "Quellen « hatten gleichwohl nur noch eine propädeutische Legitimation und 
keine verbindliche Kraft mehr. Die gesetzesgleichen Lehrbücher der großen Pandektisten, von denen der Rechtshistoriker bis heute neben Altmeister Savigny und seinem Schüler Puchta respektvoll beispielsweise Heinrich Dernburg, Rudolf von Jhering, Bernhard Windscheid zu zitieren pflegt, bezogen sich auf eine erloschene Normenwelt. In den universitären Veranstaltungen musste der römische Stoff zugunsten des Neuen deutlich reduziert werden. Die akademischen Schüler der Pandektisten konnten mit dem schlechthin Unbegreiflichen nur deshalb weiterleben, weil es ihnen gelang, unter Berufung auf den romanistischen Geist der Zivilistik, ihre Lehren als notwendige Einführung in diesen Geist zu konservieren und an die Studenten zu bringen.

Dem hatte auch die Folgezeit trotz mancherlei Anstrengungen nichts entgegenzusetzen. Theoretische Kraft und methodologische Anstrengungen konzentrierten sich auf den in Hoffnung oder mit Bangen erahnten Justizstaat der Zukunft und kreisten um Dezisionismus, freie Rechtsschöpfung und Richterethos. Im Übrigen war man mit dem ersten Weltkrieg und der ungeliebten Weimarer Republik befasst. Das römische Recht dümpelte als Rechtsgeschichte im propädeutischen Windschatten.

Mit dem Auftreten des Nationalsozialismus begann auch für das romanistische Reservat eine wirklich kritische Zeit. Denn der Nationalsozialismus hatte sich zur Freude der Germanisten vorgenommen, den weiterwesenden römischrechtlichen Geist zu bannen. »Wir fordern Ersatz für das der materialistischen Weltordnung dienende römische Recht durch ein deutsches Gemeinrecht ", lautete Punkt I9 des Parteiprogramms von I920, eine Formel, die in den völkisch-germanistisch geprägten, rechtshistorischen Populärschriften der Zeit wurzelte.

Das Programm wurde umgesetzt. Das römische Recht verschwand aus den Unterrichtsprogrammen der deutschen Fakultäten. Die führenden Romanisten, überwiegend Juden, wurden vertrieben, wobei es der NS-Propaganda sehr gelegen kam, die Beseitigung des in damaliger Diktion "artfremden " römischen Rechts mit ihren antisemitischen Aktionen verknüpfen zu können.

Aber in den Köpfen und Herzen ihrer Schüler und jüngeren Kollegen, die das Regime überlebten, überlebte auch das römische Recht. Es kehrte nach 1945 im Westen Deutschlands wieder in Form von Rechtsgeschichte an die Universitäten zurück. Denn damals bemühten sich - verständlich, aber wenig weitsichtig - 
die gereinigten oder ungereinigten älteren Mitglieder der Rechtsfakultäten um Anschluss an die Universitätsszene ihrer glücklichen Studentenzeit vor dem Ersten Weltkrieg.

Es gab in der »BRD « noch einmal drei große, unvergessliche Romanisten, Max Kaser, Wolfgang Kunkel, Franz Wieacker, die aber den Untergang des humanistischen Gymnasiums, den Verlust des humanistischen Bildungsideals und den dadurch endgültig eingeleiteten Vermoderungsprozess des römischen Rechts nicht aufhalten konnten.

Zwar wiesen bereits I 830, als die erste deutsche Übersetzung des Corpus Iuris erschien, seine Übersetzer, Dr. Bruno Schilling und Carl Friedrich Ferdinand Sintenis, in ihrem Vorwort darauf hin, »daß Viele derer, die sich Juristen nennen, nicht mehr fähig sind, im C. I. zu lesen «, was sie mit dem Umstand erklärten, dass das "Studium der Quellen auf den Akademien von Vielen sehr vernachlässigt, ja fast gar nicht getrieben « werde. Aber ihr vorrangiges Ziel war es keineswegs, diese Experten von ihrem Handicap zu befreien, wussten sie doch, dass die Mehrzahl der praktisch arbeitenden Juristen sich ohnehin mit dem »Nachlesen der so genannten Beweisstellen « begnügen konnte und begnügen würde. Hauptabsicht war, wie ihr Vergleich der Digestenübersetzung mit der Bibelübersetzung zeigt, ihren Zeitgenossen nicht länger die Grundlage der gemeinsamen Rechtsordnung vorzuenthalten, sondern sie ihnen ebenso zugänglich zu machen, wie Luther den Christen das Verständnis für die Grundlage des gemeinsamen Glaubens ermöglicht hatte.

I990, als eine immer stattlicher werdende Crew von Romanisten sich anschickte, eine zweite deutsche Übersetzung des Corpus Iuris auf den Weg zu bringen, standen Übersetzern und Rezensenten lediglich noch Argumente aus dem Vorratslager der Memorialkultur zur Verfügung.

Heute fristet das römische Recht nur noch an einigen wenigen Rechtsfakultäten eine gesamtkulturell belanglose Residualexistenz, aus der es auch die rückbesinnlich orientierten Neopandektisten, die dem amerikanisch getönten, globalen Recht trotzig ihre europäischen Würzelchen entgegenstrecken, nicht werden befreien können. 
»Denn was kriegt der Mensch von aller seiner Arbeit und Mühe seines Herzens, die er hat unter der Sonne? «

(Prediger 2.22)
Der zweite Lebenslauf beschreibt das Vocabularium Iurisprudentiae Romanae (VIR). Dieses Vocabularium war ein Langzeitvorhaben der Preußischen Akademie der Wissenschaften.

Langzeitvorhaben sind Unternehmungen, die - nach Meinung und Hoffnung - innerhalb der Lebenszeit ihrer Begründer zu Ende geführt werden können und sollen. Der Aspekt, dass die Früchte der inszenierten Arbeit erst der nächsten, übernächsten oder auch einer noch ferneren Generation zugute kommen könnten, wird allerdings in der Regel mitgedacht. Dagegen wird der ebenfalls nahe liegende Gedanke, dass diese Früchte von der entfernten Erntegeneration möglicherweise nicht mehr geschätzt werden könnten, durchgehend ausgeblendet. Insoweit eignet den Langzeitvorhaben eine normativ-pädagogische Note. Den Nachfahren wird im Namen der unsterblichen Wissenschaft das nötige Interesse verordnet.

Das Vocabularium Iurisprudentiae Romanae wurde nach genau Ioo Jahren abgeschlossen, und zwar »abgeschlossen « im Sinne von "planmäßig vollendet « und nicht etwa »beendet « in irgendeiner imperfekten Weise. Insofern und im Blick auf viele andere Unternehmungen dieser Art hat es ohne jeden Zweifel verdient, ein besonders erfolgreiches Langzeitvorhaben genannt zu werden.

Bestellt und ins Leben gerufen hat dieses Vorhaben der große Theodor Mommsen, Nordfriese und Berliner, geboren I 8 I7, gestorben I903. Beendet wurde es von Marianne Meinhart, geboren I920, gestorben 1994, Professorin für römisches Recht im österreichischen Linz.

Professor Mommsen, seit seiner Versetzung von Breslau nach Berlin im Jahre I 858 Ordentliches Mitglied der Preußischen Akademie der Wissenschaften, hatte im Jahre I 870 der Akademie und insbesondere der Juristenwelt ein kolossales Geschenk gemacht. Er legte die Edition einer Rechtssammlung vor, die unstreitig im Zentrum des damals geltenden römischen Rechts stand: die Edition der Digesten oder - wie erwähnt - der Pandekten.

Die Pandektisten, die eben dabei waren, der deutschen Privatrechtskunst Weltruhm zu verschaffen, beglückte Mommsen I 870 also mit einer historisch-kritischen Ausgabe eines wesentlichen Teiles ihres lateinischen Normenschatzes.

Historisch-kritisch bedeutet hier, dass die älteste erreichbare Textstufe für den zu edierenden Text gesucht wird, wobei der nur 
selten und für die Antike niemals erfüllbare Traum des Editors auf ein Exemplar mit der verbürgten Handschrift des Autors gerichtet ist. Ist der älteste Beleg des fraglichen Textes ausfindig gemacht, wird er mit anderen »Textzeugen «, mit Abschriften, Auszügen, Zitaten, Drucken, Kommentaren etc. »kritisch « - das bedeutet: auf der Folie dessen, was der Kritiker zu wissen glaubt - verglichen, um dann endlich in der Form publiziert zu werden, von der der Herausgeber annimmt, dass sie dem »Urzustand «, dem Produkt des historischen Autors am nächsten komme.

So problematisch dieses mit vielen Unbekannten und allerlei Hypothesen und Spekulationen belastete Verfahren offensichtlich ist - für eine Welt, die glaubt, dass es auf jedes Wort, vielleicht sogar auf jeden Buchstaben, ankommt und die bereit ist, von einem Wort und einem Buchstaben nicht nur ihr eigenes Seelenheil, sondern auch das der anderen abhängig zu machen - für eine solche Welt ist dieses Verfahren zur Konstruktion von Authentizität das einzig denkbare und vernünftige. Für die Juristen und Theologen des Abendlandes - und nicht nur für sie - war es daher schon früh der sichere Weg zur Rettung ihrer Deutungen vor der Bedrohung durch Textalternativen.

Es war zweifellos kein Zufall, dass die Pandektisten die historisch-kritische Ausgabe ihres heiligen Buches im Jahre I 870 erhielten. Denn sie hatten sich gerade mit Hilfe von Savigny und einer durch den Historismus geförderten "geschichtlichen Betrachtung " auf die Suche nach einer neuen Rechtsdogmatik begeben, die den durch die beginnende Industrialisierung gewandelten, normativen Bedürfnissen angepasst war. Da lieferte der sofort allgemein akzeptierte Mommsen-Text endlich die Jahrhunderte lang vermisste feste Grundlage, auf der, im Kampf um die richtige Auslegung der römischen Normen, ein kollektiv nachvollziehbarer, hermeneutischer Prozess in Gang gesetzt werden konnte. Mommsen hatte also ein höchst aktuelles und unmittelbar praktisches Wissenschaftsziel verwirklicht.

Um den vollen Nutzen seiner in wenigen Jahren fertiggestellten Ausgabe zu erhöhen, hatte Mommsen die Anfertigung eines Index verborum, eines Registers aller in dem großen, aber unübersichtlichen Werk enthaltenen Wörter angeregt. Fleißige Hilfskräfte zerschnitten zwei Exemplare der frischgedruckten Digesten, klebten die Wörter in alphabetischer Reihenfolge wieder auf, notierten dahinter Seite und Zeile des Fundortes in den Digesten und 
schrieben anschließend die abweichenden Lesarten nieder, welche Mommsen im kritischen Apparat seiner Edition vermerkt hatte. Das war eine mühevolle und langwierige Arbeit, die sich nahezu 20 Jahre hinzog. Erst im Mai I 888 konnte das »Ministerium der geistlichen, Unterrichts- und Medicinal- Angelegenheiten « dem »beständigen Sekretar der königlichen Akademie der Wissenschaften und ordentlichen Professor Herrn Dr. Mommsen « melden, dass das vom Ministerium seit I 880 finanziell unterstützte "verdienstvolle Werk nunmehr zum Abschluß gebracht ist«. Es wurde der königlichen Bibliothek einverleibt und sollte »dem interessierten Publikum in der für Handschriften üblichen Weise« zugänglich gemacht werden.

Dass dieses heute leider verschollene Werk jemals ein solches Publikum gefunden hat, so dass die große Mühe den gerechten Lohn erhielt, ist nicht nur ungewiss, sondern auch unwahrscheinlich.

Denn I 888, als der Index abgeschlossen wurde, hatten sich die Interessen der Wissenschaft und damit ihre Bedürfnisse einschneidend verändert. Schon zwei Jahre früher, I 886, war Mommsen selbst mit einer Denkschrift hervorgetreten, in der er vorschlug, den Index verborum, wenn er denn erst fertiggestellt sei, zu verwenden, um daraus ein Vocabularium Iuris Romani Antiquioris herstellen zu lassen.

Dieses Vocabularium sollte viel mehr werden als ein bloßer Wortindex. Ein Wortindex, mit dem man jedes in der Normensammlung vorkommende Wort, aber auch Wortverbindungen (wie ius gentium: "Völkerrecht «) oder Redensarten (wie tempus ad deliberandum: »Bedenkzeit «) auffinden kann, ist ein gutes Hilfsmittel für Juristen, die aus der ratio scripta die richtige Stelle schöpfen wollen.

Im VIR sollten demgegenüber die Wörter der Digesten nicht mehr vollständig, sondern raumsparend nach ihren Grundformen (die Fachleute sagen: lemmatisiert) verzeichnet werden. Außerdem - und das war das Entscheidende - sollten die Wörter wieder jenen antiken Autoren, aus deren Büchern Kaiser Justinian die Fragmente einstmals nach Zweckmäßigkeitsgesichtspunkten hatte ausschneiden lassen, zugeordnet werden.

Das Vocabularium würde seinen Benutzern demnach erlauben, die römischen Juristen nach ihrem Sprachgebrauch zu differenzieren und $\mathrm{zu}$ individualisieren, sie als Autoren und Persönlich- 
keiten sichtbar zu machen. Von diesen Bemühungen durfte man sich Großes erwarten. Es war bekannt, Kaiser Justinian hatte es selbst verkünden lassen, dass die Textfragmente der römischen Juristen bei ihrer Exzerpierung hier und da verändert, umgeschrieben, interpoliert und sonstwie den Bedürfnissen der byzantinischen Epoche, die bereits fünf Jahrhunderte vom Prinzipat trennte, angepasst worden waren. Wenn es nun mit Hilfe philologischer Studien gelingen würde, durch die alte Sprache auch der alten Sache habhaft zu werden, würde man das klassische (wie man es getauft hatte) römische Recht, das Recht des Prinzipats, von allen späteren Zutaten gereinigt, wie einen von allem genetischen Schmutz befreiten Diamanten vor sich sehen. Das VIR versprach die Eliminierung der justinianischen Interpolationen und damit die endgültige Reinigung der ratio scripta.

Aber zweifellos war dies ein Traum von Philologen und Historikern, nicht von Juristen. Der Schritt vom Index zum Vocabularium spiegelt die wissenschaftsgeschichtliche Entwicklung der Arbeit am römischen Recht. Es war der Schritt von der historischen Rechtsschule zur historisierenden Rechtsbetrachtung.

Mommsens Manifest von I 886 legte den Grundstein für das Vocabularium Iurisprudentiae Romanae. I 886 - also ein Jahr bevor die bereits fünf Jahre an einem Nationalgesetzbuch arbeitende Juristenkommission des Reichsjustizamtes ihre Ergebnisse präsentierte - signalisierte der mächtige Jurist und Historiker den Beginn der endgültigen Historisierung des römischen Rechts.

I 887 begann die Arbeit am Wörterbuch der klassischen römischen Rechtswissenschaft; zugleich wurde das Unternehmen im Fachblatt der historischen Rechtsschule, der Zeitschrift der Savigny-Stiftung, dem romanistischen Publikum mit Hilfe von Probeartikeln vorgestellt.

Das war genau das Jahr, in dem der erste Entwurf eines Bürgerlichen Gesetzbuches der wenig begeisterten deutschen Öffentlichkeit vorgelegt wurde, denn sie stieß sich an der rein pandektistischen Geisteswelt und dem ungebremsten römischrechtlichen Inhalt des großen Gesetzes.

I903, Mommsen war eben gestorben, erschien der erste Band des auf 5 Bände kalkulierten VIR. Er umfasste die Buchstaben A bis $\mathrm{C}$ und wurde dem Andenken Mommsens gewidmet. Seine Fertigstellung hatte nach allgemeiner Meinung viel zu lange, nämlich I7 Jahre gedauert und war von mancherlei Störungen begleitet 
gewesen. Die meisten Bearbeiter der ersten Stunde waren teils aus persönlichen, teils aus beruflichen Gründen ausgeschieden. Nur Professor Bernhard Kübler blieb noch übrig, ein Mann, von dem es in seinem Nachruf hieß, er sei der » eigentliche Hauptarbeiter « am Vocabularium gewesen.

Jetzt war man jedoch optimistisch, dass die Arbeit rasch voranschreiten werde, denn noch ahnte niemand, dass das Wörterbuch ein Langzeitvorhaben der Preußischen Akademie werden würde. Aber die Hoffnung trog. Erst im Jahre I9I4 konnten wieder zwei Faszikel erscheinen, und dann sorgten der Erste Weltkrieg und die ihm folgende Finanznot für eine drastische Unterbrechung bis 1925 .

Obwohl danach wieder mit großem Eifer und ohne Rücksicht auf die Zeitläufte an dem Wörterbuch gewerkelt wurde, gelang es bis zum Ausbruch des Zweiten Weltkrieges nicht, mehr als zwei Faszikel (I936 und 1937) und einen weiteren Band erscheinen (I939) zu lassen. Was aber vorwiegend an der mageren Sachausstattung und keinesfalls daran lag, dass etwa die Preußische Akademie der Wissenschaften sich auf den Standpunkt gestellt hätte, dass Punkt I9 des amtierenden Parteiprogramms eine Arbeit am römischen Recht obsolet gemacht hätte.

Nach dem Zweiten Weltkrieg war das Wörterbuch zwar nicht vergessen, aber arbeiten mochte so recht niemand mehr an ihm. Denn das, was eine I953, gleichzeitig mit dem Beginn der bundesrepublikanischen Restauration publizierte Geschichte des römischen Rechts vortrug, nämlich: "Alle Studien, insbesondere alle textkritischen und interpolationistischen, aber auch alle aus irgendwelchen geschichtlichen Anlässen betriebenen Wortstudien, ... werden für die Juristenschriften ... und ... für die Digesten selbst ein unschätzbares Hilfswerk in dem leider noch unvollendeten Vocabularium Iurisprudentiae Romanae zur Hand haben « - eben diese Bekanntmachung fand die große Mehrheit der Romanisten nur noch mäßig interessant. Textkritik und Interpolationenforschung schickten sich an, einem neuen Textverständnis zu weichen, und nur wenige glaubten noch, besser als ein Römer zu wissen, was korrektes Juristenlatein war.

So erschien denn erst I964, nach 25-jähriger Pause, wieder ein Faszikel des Vokabulars und es dauerte weitere I 5 Jahre, also bis I979, bis die nächste Lieferung den inzwischen für das römische Recht nur noch mühsam zu begeisternden Buchmarkt erreichte. 
Danach ging es jedoch wirklich rasch. Allerdings nicht deswegen, weil die wissenschaftlichen Bedürfnisse der Romanisten die Wende erzwungen hätten. Ein kleiner lateinischer Satz in den Vorreden erklärt das unerwartbare Tempo: adhibitum est auxilium machinae computatoriae! Das elektronische Zeitalter hatte das sterbende römische Recht erreicht.

I983, I985 und I987 erschienen die noch fehlenden Teile des Wörterbuchs, so dass nach genau Ioo Jahren das Langzeitvorhaben tatsächlich seinen Abschluss fand.

III.

Der nächste Lebenslauf gehört Bernhard Kübler. Er wurde am 4. Juli I 859 geboren, war also 42 Jahre jünger als Mommsen, ohne den sich allerdings sein Leben zweifellos andere Wege gebahnt hätte.

Sohn des Direktors am königlichen Wilhelmsgymnasium in Berlin, absolvierte er die väterliche Schule und studierte anschließend klassische Philologie an der Friedrich-Wilhelms-Universität. I88I, im seinerzeit üblichen Durchschnittsalter von 22 Jahren, wurde er zum Doktor der Philologie promoviert. Danach ergriff er, wie es für die braven klassischen Philologen des ausgehenden I9. und beginnenden 20. Jahrhunderts nahezu die Regel war, den Beruf des Gymnasiallehrers. Er unterrichtete an verschiedenen Berliner Gymnasien. Das letzte, an dem er von I 895 bis 1902 tätig sein konnte, war das seiner Liberalität wegen gerühmte Askanische Gymnasium. Dieses, als »Askanische Oberschule in Berlin-Tempelhof " heute noch existierende Gymnasium, war seinerzeit eine renommierte, neuhumanistische Lehranstalt, deren Rektor, ein Altphilologe, was das gründliche und umfassende Erlernen der alten Sprachen betraf, keinen Spaß verstand. Der junge Kübler war also nachhaltig damit beschäftigt, den ihm anvertrauten Jugendlichen Grammatik, Wortschatz und Textüberlieferung der Antike einzubläuen.

Diese Tätigkeit füllte ihn offenbar nicht aus. Denn schon I 887 , also von der ersten Stunde an, arbeitete er am Vocabularium Iurisprudentiae Romanae mit. Als das Unternehmen in der Savigny-Zeitschrift bekannt gemacht wurde, wird Dr. Bernhard Kübler als einer der drei mit der »Ausführung der Arbeit « befassten Wissenschaftler erwähnt.
»Und mich verdroß alle meine Arbeit, die ich unter der Sonne hatte, daß ich dieselbe einem Menschen lassen müßte, der nach mir sein sollte. Denn wer weiß, ob er weise oder toll sein wird? Und soll doch herrschen in aller meiner Arbeit, die ich weislich getan habe unter der Sonne."

(Prediger 2.I 8,I9) 
Den Auftrag dazu hatte Mommsen erteilt. Ihm war der Philologe, der schon als Student seine Vorlesungen besucht und sich für römisches Justiz- und Militärwesen interessiert hatte, nicht mehr aus den Augen geraten. Und als Kübler sich I 89 I bei der philologischen Fakultät habilitiert hatte und gleichzeitig - nicht zuletzt wegen seines immensen Fleißes - zur tragenden Stütze im Herausgeberkreis des Vokabulars avanciert war, bereitete der Altmeister in aller Stille einen unerhörten Coup vor.

Die juristische Fakultät der Universität Greifswald wurde bewogen, dem durch fachlich Juridisches bislang nicht sonderlich aufgefallenen Kübler einen juristischen Ehrendoktor zu verleihen. Damit war die formale Voraussetzung dafür geschaffen, dass der Privatdozent der Philologie ein an der juristischen Fakultät der Friedrich-Wilhelms-Universität von Mommsen vorsorglich eingefädeltes und durchgesetztes Extraordinariat erhalten konnte.

Das alles ereignete sich im Jahre I900, das Jahr, in dem bereits mit dem Bürgerlichen Gesetzbuch die Fanfare des Wandels in der Romanistik geblasen wird. Der Umstand, dass ein reiner Philologe als Professor für römisches Recht in eine juristische Fakultät überwechseln konnte und nach kurzer Zeit damit begann, Vorlesungen nicht nur im römischen, sondern auch im (neuen) bürgerlichen Recht zu halten, ist überaus erhellend für den Platz und das Befinden des römischen Rechts im Deutschland der Jahrhundertwende.

Noch lagen römisches und bürgerliches Recht so nahe beieinander, dass das eine durch das andere interpretiert werden konnte. Das (jetzt) geltungslose geschichtliche Recht, das geltende (noch) geschichtslose Recht und die Geschichte des Rechts hängen noch für fast ein Jahrzehnt nahezu ununterscheidbar aneinander. Dann verschwindet das geschichtliche Recht nicht nur aus den justiziellen Dezisionen, sondern auch aus den gelehrten Erörterungen der Dogmatiker der geltenden Normenwelt. Die Geschichte des Rechts mutiert in kleinen Schritten zur Rechtsgeschichte. Das 20. Jahrhundert wird das Jahrhundert einer allmählich immer radikaleren Historisierung der Rechtsbeobachtung.

Zunächst wird diese Beobachtung kontextualisiert, wie man heute vielleicht sagen würde, wenn man das Heranreifen der Einsicht bezeichnen möchte, dass in der Antike nicht nur Rom und das Recht der Römer existierten, sondern dass es auch Griechen und Ägypter gab - ein Vorgang, der schließlich dazu führte, dass die 
Romanisten die antike Rechtswelt beginnend bei Ur und Akkad und endend in Byzanz zu bearbeiten begannen. Zum anderen führte die Suche nach den Interpolationen in der überlieferten Textmasse des römischen Rechts, Forschungen, für die das VIR seine Hilfsdienste anbieten sollte, schneller in eine Sackgasse als das Wörterbuch vorankam.

Der Weg in die Sackgasse war ausgeschildert durch eine Reihe von Hypothesen, zu deren Zusammenbruch Bernhard Küblers umsichtige historisch-philologische Arbeit manches Bauelement beitrug. Dazu gehörte die Vorstellung, die römischen Juristen hätten eine bestimmte, nämlich »klassische " Einheitssprache gesprochen, deren »unklassische « Störung spätere, fremde Eingriffe - Interpolationen eben - verrate; dazu gehörte die Ausblendung der Überlieferungsgeschichte der Texte zwischen dem 2. und dem 5. Jahrhundert, weil man allen Textwandel als Folge intentionaler Eingriffe der Bürokraten Justinians ansah; dazu gehörte die Idee, dass es sich beim römischen Recht um eine unpersönliche, weitgehend harmonisch geschlossene Menge abstrakter Dogmen, nicht um ein vielstimmiges Konglomerat juristischer Meinungen und Argumentationen gehandelt habe.

Altertumswissenschaftliche Methode und philologische Feinarbeit destruierten diese Annahmen Schritt für Schritt. Sie destruierten damit zugleich das Fundament, auf dem das Vocabularium siedelte, und sie führten die romanistischen Lehrstuhlinhaber des 20. Jahrhunderts in die Schizophrenie, sich zwischen den Methoden historischer Feinanalyse und den Herausforderungen pragmatischer Rechtskonstruktion aufspalten zu müssen.

Was Theodor Mommsen konnte und was zu Beginn des Kübler'schen Berufslebens noch möglich war, nämlich Historiker und Jurist $\mathrm{zu}$ sein, wurde rasch unmöglich. Selbst wenn alle Romanisten - was bekanntlich nicht der Fall war - Mommsens Genialität besessen hätten, wären sie nicht zur gleichzeitigen Arbeit als Nomotheten der Rechtsdogmatik und als Idiographen der antiken Rechtsgeschichte in der Lage gewesen.

Doch damit bin ich weit vorausgeeilt im wüsten 20. Jahrhundert. Zunächst sind wir noch im Jahre I900, in dem Bernhard Kübler bei den Juristen ein Extraordinariat erhielt, das aber schon ein Jahr später in eine planmäßige Professur umgewandelt wurde. Noch im selben Jahre I900 übernahm Kübler, nachdem alle Mitherausgeber, sei es aus beruflichen, sei es aus persönlichen Gründen 
ausgeschieden waren, auch die Alleinredaktion des VIR. Der "Kernpunkt « in seiner Lebensarbeit, wie es in einem Nachruf heißt, ist erreicht.

Die Dinge ließen sich auch gut an. Geld war vorhanden. Im Jahre I900 feierte die Preußische Akademie der Wissenschaften ihr 20ojähriges Bestehen und blickte voller Stolz auf ihre von Harnack für den Festtag verfasste Geschichte. Der deutsche Kaiser und preußische König will die Akademie und in ihr besonders Theodor Mommsen ehren. Wie ehrt man einen 83-jährigen, dem schon alle Ehrungen, mit dem die Zeit einen Wissenschaftler ehren kann, zugefallen sind? Man bezeichnet dem Kaiser das Vocabularium als einen wissenschaftlichen Gegenstand, der seiner Munifizenz würdig sei. Aus dem Allerhöchsten Dispositionsfonds fließen 60.000 Mark, die das Unternehmen finanziell absichern. Eine stattliche Herde von 300 durchschnittlich schweren Milchkühen hätte man sich für diese Summe auf dem Viehhof in Berlin-Friedrichsfelde kaufen können. Und Bernhard Kübler darf dieses Geld ausgeben.

Er heuert Hilfskräfte und Mitarbeiter an und kann, da er rastlos selbst Hand anlegt und der wortmonographischen Darstellungen nicht überdrüssig wird, beispielgebend und motivierend das Wörterbuch vorantreiben.

I9I2, schon 53jährig, verließ Kübler Berlin und nahm einen Ruf an die stille Universität Erlangen an, wo er I 934 - im damals noch im Bereich des Üblichen liegenden Alter von 75 Jahren emeritiert wurde. Wie er sich zur gerade ein Jahr alten, neuen deutschen Welt stellte, ist nicht bekannt. Seine Arbeit am Wörterbuch setzte er jedenfalls zielstrebig fort. Aber es wird ihm wohl kaum entgangen sein, dass, wie die Preußische Akademie der Wissenschaften dem Verleger Walter de Gruyter anlässlich einer Kalkulation für das Vokabular schrieb, das Aufbringen von $\mathrm{Zu}$ schussbeiträgen für ein Wörterbuch des römischen Rechts »heute ganz besonders schwer" geworden war.

I935 wurde Kübler, reichlich spät, zum korrespondierenden Mitglied jener Akademie ernannt, die das öffentlich immer weniger als Desiderat empfundene Wörterbuch herausgab.

Der Vizepräsident der Akademie, Geheimrat Ernst Heymann, Direktor des Berliner Kaiser-Wilhelm-Instituts für ausländisches und internationales Privatrecht, schrieb I940, anlässlich des überraschenden Todes des mittlerweile 80-jährigen Alleinredaktors, nachdem er den auch heute noch üblichen Floskeln von der »ent- 
sagungsvollen Arbeit « und der »kaum auszufüllenden Lücke« Genüge getan hatte: »Bernhard Kübler war unser Mitglied und hat einen großen Teil seines rastlosen Fleißes unserem von Theodor Mommsen begründeten Vocabularium Iurisprudentiae Romanae gewidmet. Er hat dieses Werk nahe an die Vollendung geführt.«

Aber vollendet war es eben doch nicht. Marte nam furente, heißt es noch 45 Jahre später in der abgründigen Sprache der Disziplin, omne hoc opus iacuit: weil Mars wütete, blieb das ganze Werk liegen.

Die Akademie gründete, da der Hauptarbeiter, »der sein Leben lang diese Last « trug, gestorben war, eine aus den Mitgliedern Heymann, Koschaker und Stroux bestehende Akademiekommission, deren Wirken, wenn es ein solches je gab, keine Spuren hinterlassen hat.

Als das Vokabular, nach dem kleinen Zwischenspiel von I964, endlich in seine letzte Runde ging, waren die Kommissionsmitglieder ausnahmslos längst gestorben, die Akademie hieß nicht mehr »Preußische «, sondern war unaufhaltsam DDR-deutsch geworden und wurde 1972 »Akademie der Wissenschaften der DDR « getauft. Die noch nicht abgearbeiteten Materialien befanden sich nicht mehr in Berlin, sondern lagen in Marburg.

In Deutschland war offenbar niemand bereit, das Vermächtnis Mommsens anzunehmen. Marianne Meinhart, die engagierte und weitsichtige Romanistin der Johannes Kepler Universität Linz, ließ sich schließlich mit der Arbeit betrauen. In einer Einleitung schrieb sie kühl, sie habe die - früher für das Essentiale gehaltenen Interpolationsvermutungen weggelassen. Warum? Weil, quae arbitria adnotari ad disciplinam Iurisprudentiae Romani haud tanti refert. In grobem Deutsch: Die Sache bringt nichts mehr!

Der anfängliche Seinsgrund des Vokabulars war also mittlerweile zum unnützen Zierrat mutiert, ohne dass eine neue Rechtfertigung auch nur angestrebt worden wäre. Die Sache verstand sich offenbar aufgrund ihrer langen Dauer von selbst.

Die Nachwirkungen des Lebenswerks von Kübler entsprachen dem stillen und blassen Ende des Vorhabens. Für die wissenschaftliche Welt hatte es mit einigen wortkargen Abschlusshinweisen in den Fachzeitschriften sein Bewenden. 
»Es ist eine Eitelkeit, die auf Erden geschieht: es sind Gerechte, denen geht es, als hätten sie Werke der Gottlosen - und sind Gottlose, denen geht es, als hätten sie Werke der Gerechten. Ich sprach: Das ist auch eitel.

(Prediger 8.14)
Der vierte Lebenslauf drängt sich in einem Brief zusammen, der dem heutigen Leser das Herz zerreißt. Dieser Brief ging im Dezember I94I, wenige Tage vor Weihnachten bei der Preußischen Akademie der Wissenschaften ein.

Datiert war das Schreiben auf den I9. Dezember. Am Tag zuvor, am I 8. Dezember I94I, hatte der Schreiber sein 55 . Lebensjahr vollendet. Der mit Schreibmaschine auf gutem, noch heute unvergilbtem Papier geschriebene Brief lautet folgendermaßen:

Preußische Akademie der Wissenschaften

Berlin NW 7

Unter den Linden 8

Als früherer rechtshistorischer Mitarbeiter der Akademie der Wissenschaften erlaube ich mir ergebenst, folgende Bitte vorzutragen:

In 30-jähriger Mitarbeit am Wörterbuch der römischen Rechtssprache habe ich einen wissenschaftlichen Apparat an Druckbögen, Druckfahnen, Manuskripten, Hilfszetteln und Büchern zusammengebracht, der für die Fortsetzung des Werkes von Bedeutung sein dürfte. Daneben habe ich an anderen Unternehmungen der Akademie wie z. B. »den Gesetzen der Angelsachsen « mitgearbeitet, woraus sich ähnliche Materialien ergeben haben. Ich habe auch zwei von der Berliner Rechtsfakultät preisgekrönte Arbeiten rechtsgeschichtlichen Inhalts verfaßt, die im Manuskript vorliegen. Zu ihrer Fortführung habe ich Materialsammlungen zusammengebracht, die z[um] T[eil] in Kartothekform vorhanden sind. Endlich habe ich auf Anregung des inzwischen verstorbenen Prof[essors] Bernhard Kübler die »Institutionen Justinians « zur Vorbereitung eines Wörterverzeichnisses verzettelt, wobei jedes Wort des Werkes ausgeschrieben und sein Fundort vermerkt ist.

Da bei den für mich bestehenden Verhältnissen mit dem Verlust dieser Materialien zu rechnen ist, wenn sie nicht anderweitig untergebracht werden, ich aber andererseits hoffe, daß sie in berufener Hand noch zur Fortführung der begonnenen Arbeiten beitragen können, erlaube ich mir die Bitte auszusprechen, diesen wissenschaftlichen Apparat der Akademie zur hochgeneigten Verfügung übergeben zu dürfen.

Paul Israel Abraham

Jüdische Kennkarte Berlin A I 56453

Das einen Tag nach seinem Geburtstag formulierte Angebot des ehemaligen Mitarbeiters brachte die Akademie deutlich in Verlegenheit. Gerade hatte sie den Juden unauffällig aus ihrem Gesichtsfeld geschafft, da brachte er sich mit seinem, wie sie es formulierte: Antrag auf »Übernahme von Material« peinlich in Erinnerung. Obendrein in der offenkundigen Absicht, eine Art von Lebenswerk, das offenbar von dem des soeben hochgeehrt und 
hochverehrt gestorbenen Herrn Kübler nicht sonderlich verschieden war, der Akademie zu schenken und es dadurch für die Wissenschaft zu retten.

Die Empfindungen der Verantwortlichen schwankten zwischen Bangigkeit und Genugtuung. Einerseits wurde ihnen schon bei der Wendung »übergeben zu dürfen « äußerst unwohl. Denn das schien doch zu bedeuten, dass der Jude mit seinem Stern und seiner vorweggenommenen Hinterlassenschaft in der Akademie als Schenker aufzutauchen beabsichtigte. Denn auf etwas anderes als auf die bevorstehende Deportation konnte mit der Wendung »bei den für mich bestehenden Verhältnissen « kaum angespielt worden sein. Man würde ihn empfangen und sich irgendwie bedanken müssen. Das konnte schwer kalkulierbare, politische Folgen haben. Andererseits war es kostbare »Wissenschaft «, die da kostenlos angeboten wurde. Wissenschaft, an der die Akademie nicht nur pflichtgemäß, sondern existentiell ein großes Interesse zu haben hatte.

Es bestand Handlungsbedarf, und Vizepräsident und Geheimrat Heymann handelte. Wie er handelte, kann man einer am 6. Januar 1942 verfassten Aktennotiz entnehmen:

»Da ich eine Durchschrift des Schreibens von A. erhalten hatte, habe ich mich sofort mit Herrn Dr. Schwarz in Verbindung gesetzt, der in meinem Auftrage an A. geschrieben hat, daß er zu ihm kommen und sich die Sachen ansehen werde, um Näheres zu verabreden. Die angebotenen Arbeiten, die im Zusammenhange mit A.'s früheren Arbeiten für das Vocabular entstanden sind, sind (zum Teil mindestens) offenbar sehr wertvoll. Das gilt vor allem vom Index über die Institutionen Justinians, die ja leider für das Vocabular von Mommsen nicht mit verzettelt worden sind und für die min[destens?] ein gedruckter einfacher Index wie für den Codex später ge[setzt?] werden muß.

Die Unterredung des Dr. Schwarz mit A. konnte aber nicht stattfinden, da A. schrieb, daß er krank geworden sei. Dr. Schwarz hat ihm noch einmal geschrieben, aber keine Antwort erhalten. Er wird jetzt sogleich noch einmal schreiben, daß die Akademie das Angebot annimmt und daß er über die Modalitäten noch mit Herrn A. sprechen wolle, sobald dieser wieder einigermaßen gesund ist. Die Modalitäten bestehen (nach näherer Prüfung der Manuskripte) darin, daß wir als Akademie das volle Eigentum und das volle Urheberrecht an den Sachen erwerben würden und dafür aber auch einen angemessenen Betrag bezahlen würden, aus Gründen, die ohne weiteres am Tage liegen."

Was da so ohne weiteres »am Tage« lag, war der Umstand, dass »der A. «, von und mit dem Herr Doktor Schwarz auftragsgemäß zu sprechen geneigt war, im Begriff stand, zu verhungern. 
Zwei Bittbriefe hatte Paul Abraham im Juli und Oktober des Jahres I93 8 an den Vizepräsidenten geschickt, um seine bevorstehende Entlassung vielleicht doch noch abzuwenden. Schließlich hatte er am 3 r. Mai 1935 im Namen des Führers und Reichskanzlers Adolf Hitler das vom Reichspräsidenten Generalfeldmarschall von Hindenburg gestiftete »Ehrenkreuz für Frontkämpfer « erhalten. Aber das Kreuz hatte nur einen Aufschub erwirkt und nicht helfen können. Ab Januar 1939 musste Paul Abraham sich Paul Israel Abraham nennen. Wenig später wurde er umstandslos aus seinem Werkvertrag entlassen. Zu diesem Zeitpunkt hatte er 30 Jahre lang in der Akademie gearbeitet.

30 Jahre, denn 1909 hatte Professor Kübler den Studenten Paul Abraham im Tone höchsten Lobes als selbständigen Bearbeiter für den 3. Band des VIR vorgeschlagen. Küblers Lob war gut begründet. I 895 hatte er seinen Dienst am Askanischen Gymnasium angetreten. I 896, ein Jahr später, begann der kleine Paul, der I 886 in Berlin geborene Sohn von Adolf und Helene Abraham, in derselben Schule das neuhumanistische Curriculum und wurde, nicht zuletzt durch seinen Lehrer Kübler, mit allen Standpunkten und Visionen des kaiserzeitlichen Humanismus gründlich vertraut gemacht.

Paul lernte zunächst hingebungsvoll und sehr erfolgreich. Erst als sein Vater gestorben war und der Schüler seinen Fleiß zwischen der Schule und der Unterstützung seiner alleinerziehenden Mutter teilen musste, ließen seine Leistungen allmählich nach. Dass Paul Abraham I905 ein mittelmäßiges Abitur (als I 4. von 22 Schülern) machte, entging allerdings dem emsigen Professor Kübler, der inzwischen schon drei Jahre ausschließlich der Universität diente, ebenso wie dessen Studienbeginn an der philosophischen Fakultät. Erst als der junge Mann nach einem Studienwechsel bei den Juristen auftauchte und sich durch herausragende, von der Rechtsfakultät zweimal preisgekrönte rechtshistorische Leistungen bekannt machte, erinnerte er sich. Was zugleich seine Begehrlichkeit weckte. Denn schon damals war eine Seltenheit, was heutzutage auf den Juristenlehrstühlen längst ausgestorben ist: juristisch, historisch und philologisch in gleicher Weise geschulte und kompetente Wissenschaftler.

Paul Abraham verspricht, noch einmal eine solche Ausnahmeerscheinung $\mathrm{zu}$ werden. Er studiert mit der Hilfe eines vom Askanischen Gymnasium ausgesetzten Stipendiums, das er, auch 
um die Mutter nicht verhungern zu lassen, durch allerlei Nebenarbeiten aufbessert. I909 läuft das Stipendium aus. Paul muss sich nach Ersatz umsehen und bewirbt sich, wie nahe liegt, bei Kübler um eine Anstellung bei dem finanziell gut ausgestatteten VIR. Kübler ist entzückt.

Die Anstellung eines Studenten in einem Akademievorhaben dieses Ranges ist allerdings keine einfache Sache. Kübler rechnet mit Schwierigkeiten und bereitet seinen Antrag mit größter Sorgfalt vor. Gleichwohl gerät die Beratung über einen Werkvertrag für Paul Abraham zum Musterfall für akademische Seiltänze, wie sie auf diesem Felde bis heute getanzt werden. Fachliche Qualifikation? Über jeden Zweifel erhaben! Verantwortungsbewusstsein? Professorale Kontrolle ist gewährleistet. Keine Zertifikate? Formalismen, die nachgeholt werden können. Verzögerung des Studiums? Ermahnung zu doppeltem Fleiß.

Der Bedarf der Etablierten und die Not des Bedürftigen setzten sich durch: Am 24. Januar I9 Io erhält Abraham den erhofften Werkvertrag. Seine Arbeit am VIR beginnt; eine anstrengende und entsagungsvolle Arbeit, die ihn durch sein ganzes, von Entbehrungen und Verzicht gezeichnetes Leben begleiten wird, die ihn spezialisiert, ausfüllt und auffrisst.

»Ein schönes inniges Familienleben, gesegnet von Kindern ", wie es dem humanistisch allseits gebildeten Hauptredaktor bescheinigt wurde, hätte der Hilfskraft Abraham sicher auch gefallen. Aber bis zum Tode der Mutter, im Jahre I925, war bei dem kargen Lohn nicht an Frau und erst recht nicht an Familie zu denken. Als aber die Mutter starb und das ökonomisch unergiebige Krawattenlädchen in der Wilmersdorferstraße geschlossen werden konnte, war Paul fast 40 Jahre alt und längst ein einsamer, mit Armut reichlich vertrauter Wissenschaftsarbeiter geworden, dem niemand in einem Nekrolog, wenn er denn einen solchen erhalten hätte, hätte nachrufen können, er sei, wie sein Arbeitsstellenleiter, ein »Genosse froher Stunden« gewesen, »zu heiterem Lebensgenuß bereit"

Paul erhielt aber keinen Nekrolog. Zunächst bekam er ein amtliches Schreiben, dessen Entwurf Ernst Heymann den Akten anvertraut hat:

»Auf Ihr Schreiben vom I9. Dezember erwidert die Akademie mit bestem Dank, daß sie Ihr Angebot ihr Ihren dort bezeichneten wissenschaftlichen Apparat zur Verfügung zu übergeben an[nimmt]. Herr Dr. Schwarz wird im 
"Das Ende eines Dinges ist besser denn sein Anfang. Ein geduldiger Geist ist besser denn ein hoher Geist.«

(Prediger 7.8)
Auftrag des Vorsitzenden der Vocabularium Kommission, H[errn] H[eymann], sobald Sie wieder gesundheitlich dazu in der Lage sind, über die Modalitäten der Übergabe und ein etwaiges Honorar das Nähere besprechen."

$\mathrm{Zu}$ der Besprechung des "Näheren « kam es nicht. Es wurde überhaupt nicht mehr gesprochen. Heymann sprach sowieso nicht. Kübler konnte nicht mehr sprechen, denn er war gestorben. Als er noch lebte, war auch nicht gesprochen, sondern lediglich einsilbig geschrieben worden. Technische Korrespondenz in veränderter Sprache. Aus dem "lieben Paul Abraham" war angesichts der »bestehenden Verhältnisse « dann doch der »sehr geehrte Herr Dr. Abraham" geworden. Humanistische Umsicht des großen Humanisten. Herr Dr. Schwarz sprach auch nicht. So sehr lag ihm der kranke Jude Abraham, dessen Nachfolger er geworden war, schließlich nicht am Herzen. Das »Kriegsjahr " 1942 verstrich.

Am 26. Februar 1943, wurde Paul Abraham zusammen mit I094 Opfern im sogenannten 30. Judentransport nach Auschwitz gefahren und ermordet.

Zwei Monate später, im Mai 1943, holte Fritz Schwarz das angebotene Material aus der verlassenen Wohnung seines Vorgängers ab, brachte es in die Akademie und damit vor den Bomben, die Abrahams ehemaliges Heim alsbald zerstörten, in Sicherheit. Damit war gewährleistet, dass das Langzeitvorhaben seiner glücklichen Vollendung entgegengehen konnte.

V.

Der letzte Lebenslauf, der für die Geschichte vom Vocabularium Iurisprudentiae Romanae, einem Unternehmen, dessen Zeit vorbei war als sie kam, ausgeschnitten werden soll, ist der des schon mehrfach erwähnten Fritz Schwarz. Als er am I6. Juli 1905 geboren wurde, war Paul Abraham schon I 8 Jahre alt. Und I924, als Abraham kurz vor dem Tod seiner Mutter Helene in eine Zweizimmerwohnung in der Schönhauser Allee I38/I39 zog, immatrikulierte sich Schwarz gerade an der juristischen Fakultät der Berliner Universität, eine Entscheidung, der er aber keinen dauerhaften Geschmack abgewinnen konnte. Er ging zur Altphilologie über und promovierte 1932 bei dem klassischen Philologen Eduard Norden (I868-I94I), der damals und bis zu seiner Entlassung im Jahre I935 Rektor der Friedrich-Wilhelms-Universität gewesen ist. Seinen Schüler Schwarz dürfte dieser Vorgang nicht 
sonderlich gerührt haben, denn er war schon 1933 Mitglied der NSDAP geworden.

Begegnet sind sich Abraham und Schwarz vermutlich im Jahre 1934, als Schwarz, der eben die Staatsprüfung für das »Lehramt an höhern Schulen « abgelegt hatte, als Werkvertragsmitarbeiter zum VIR stieß. Abraham hatte I930 das zweite Heft (ignarus - in) des dritten Bandes $(\mathrm{H}-\mathrm{M})$ fertiggestellt. Nach Küblers damaliger Disposition sollte er diesen dritten Band insgesamt zu Ende führen. Aber die Herrschenden gestatteten ihm nur noch den Druck seines dritten Faszikels (inaedificatio - ipse) zu erleben (1937). Seine Arbeit am 4. Heft (ira ff.) wurde durch die Entlassung beendet (I939).

Ein Jahr zuvor hatte Schwarz, dem auch der Schuldienst keine große Begeisterung abnötigte, sein einstmals abgebrochenes Jurastudium wieder aufgenommen (1938). Damit qualifizierte er sich endgültig für Lehraufträge an der Berliner juristischen Fakultät, wo er den knapper werdenden Studiosi eine "Einführung in die römischen Rechtsquellen « anbot. Allerdings konnte man damals so wenig wie heute von Lehrauftrag und Hilfskrafttätigkeit leben, weshalb er 1939, als sein Kollege Abraham seinen Arbeitsplatz verlor, bei der »Reichsgruppe Industrie « als Referent für Arbeitsund Wirtschaftsrecht eintrat, um sich »die entsprechende wirtschaftliche Grundlage« zu schaffen.

Tätigkeit in der Wirtschaftsverwaltung, universitäre Lehre, Jurastudium und Vorbereitung einer juristischen Dissertation, die im Wintersemester I942/43 bei Paul Koschaker erfolgte, schließlich auch noch die Absicht, sich für römisches Recht zu habilitieren - da blieb eigentlich wenig Zeit für das Vokabular. Was schlimm war, denn dort standen im Jahre I 940 die Dinge nicht zum Besten. Abraham war verloren, Kübler gestorben und die Akademiekommission (Heymann, Koschaker, Stroux) musste an seiner Stelle Leitungsentscheidungen treffen. Sie beauftragte Dr. Fritz Schwarz, den langjährigen und erfahrenen Mitarbeiter, die Arbeit unter ihrer Leitung fortzusetzen und zu beaufsichtigen. So erbte Fritz Schwarz nicht nur den Buchstaben »I«, beginnend bei »ira «, sondern auch die Aufsicht über den Rest.

Das schien ihn für ein festes Angestelltenverhältnis bei der Preußischen Akademie der Wissenschaften zu bestimmen, womit seine ökonomischen Sorgen fürs Erste bereinigt gewesen wären. Aber über seinen diesbezüglichen Antrag aus dem Jahre 1942 
konnte nicht mehr befunden werden, da er am 25. Juni I 943 , einen Monat nachdem er Abrahams Materialien aus der Schönhauser Allee abgeholt hatte, zur Wehrmacht einberufen wurde.

Schwarz verschwand im Krieg. Der Geheimrat Ernst Heymann, der, als die Todesreise Abrahams amtlich wurde, pflichtschuldig in den Akten vermerkte, dass dieser inzwischen "evakuiert" worden sei, zog im gleichen Jahr mit seinem KaiserWilhelm-Institut für ausländisches und internationales Privatrecht nach Tübingen um, wo er im Mai 1946 starb.

Paul Koschaker, den mehr mit nationalsozialistischem Gedankengut verband als er glauben mochte, hatte sich schon I94I grollend aus Berlin nach Tübingen auf den Weg gemacht, wo er I946 emeritiert wurde. Nur der Latinist Johannes Stroux blieb am Entstehungsort des VIR, in Berlin.

Und der Orientalist Professor Helmuth Scheel, der »Akademiedirektor ", arbeitete an einem umfassenden Auslagerungsplan, um die wissenschaftlichen Arbeitsmaterialien, das Archiv und die Bibliothek vor den bevorstehenden Verwüstungen zu retten. Scheel, ehemals Amtsrat im Preußischen Ministerium für Wissenschaft, Erziehung und Volksbildung, war 1939 in das neugeschaffene Amt des Akademiedirektors der Preußischen Akademie der Wissenschaften eingerückt, eine Funktion von der Art, wie sie heute ein »Generalsekretär « ausübt, der für die gesamte Geschäftsführung der Akademie zuständig ist. In dieser Funktion hatte er schon die Bergungsaktion der Arbeitsunterlagen aus Abrahams Wohnung mit dem schamlosen Vermerk quittiert: »Das gesamte Material ist nach Abwanderung des Hr. Abraham übernommen worden." Jetzt lag das Schicksal des Vokabulars in seinen Händen.

Die Zettel und Manuskripte wurden in zehn Kisten verpackt und zunächst in einem Akademiegebäude in Spreeau-Sieverslake (Niederbarnim) untergebracht, von wo sie zusammen mit zahlreichen anderen Akademiematerialien nach Schönebeck an der Elbe wanderten. Dort, in der Glocke I I des Moltke-Schachts im Bergwerk der Preußag, überlebten sie den Krieg.

Überlebt hatte auch Dr. Schwarz. Er kam irgendwie aus dem Krieg und nach seinem Wohnort Berlin zurück. Die Stelle bei der Reichsgruppe Industrie war naturgemäß entfallen. Aber an der Akademie kroch schon neues Leben aus den Ruinen. Schließlich gab es, wie überall, so auch in der Wissenschaft und der Akademie keine »Stunde Null«. Die Preußische Akademie hatte in Berlin 
immerhin noch I 5 lebende und lebendige Mitglieder, gab sich schon einen Monat nach dem Untergang des Dritten Reiches eine neue Satzung als Nationalakademie, entledigte sich einiger besonders innig mit den Nazis verbunden gewesener Kollegen und wählte ebenfalls noch im Juni 1945 Johannes Stroux zum kommissarischen Präsidenten.

Überlebt hatte auch Helmuth Scheel, der sich sofort nach Kriegsende beim Berliner Senat und der SMAD, der sowjetischen Militäradministration Deutschland, für die Wiedereröffnung der Akademie einsetzte. Gleichzeitig begann er mit der SMAD Verhandlungen über die Rückgabe der ausgelagerten oder auch beschlagnahmten Akademiematerialien. Schon im Januar 1946 wurde eine größere Menge wissenschaftlicher Unterlagen und anderes Vermögen der Preußischen Akademie, die sich seit einem Monat "Akademie der Wissenschaften zu Berlin « nannte, nach Berlin zurückgebracht. Das Vokabular war nicht dabei. Aber vergessen war es nicht. In einem vorläufigen Arbeitsplan vom März 1946 wurde bereits erwähnt, dass die vorbereitenden Arbeiten zur Weiterführung des VIR aufgenommen worden seien. Fritz Schwarz konnte hoffen und machte sich einstweilen nützlich.

Die Dinge entwickelten sich gut. Mit Befehl Nr. I87 der SMAD vom I. Juli 1946 wurde die Wiedereröffnung der Akademie gebilligt, der erneut geänderte Name »Deutsche Akademie der Wissenschaften zu Berlin« (DAW) gutgeheißen und Johannes Stroux, der inzwischen am verordneten Sozialismus Geschmack gefunden hatte, als Präsident bestätigt. Am I. August I 946 erfolgte die feierliche Wiedereröffnung, und just an diesem Tage erhielten Stroux und Scheel die Nachricht, dass in den folgenden Tagen in Berlin-Rummelsburg etwa 2000 Kisten Lagerungsgut übernommen werden könnten, unter denen sich auch die zehn Kisten mit den Materialien des Vokabulars befanden.

Mit der Überwachung der Rückführung wurde Fritz Schwarz beauftragt. Er stellte fest, dass nur eine der zehn Kisten zerstört, ihr Inhalt aber gleichwohl gerettet worden sei, so dass das ganze Material wohl in Unordnung, jedoch erhalten war. Die Welt des Vokabulars schien wieder heilen zu wollen.

Für die Welt des Helmuth Scheel galt dies nicht. Er hatte Ende I945 die Entnazifizierungskommission beim Magistrat der Stadt Berlin nicht unbelastet passiert und war deshalb im Januar 1946 von Stroux entlassen worden. Eine Chance auf Wiedergewinnung 
seiner alten Position bestand angesichts der ostdeutschen Humorlosigkeit gegenüber ehemaligen Nationalsozialisten und im Hinblick auf die unübersehbaren Vorboten des kalten Krieges nicht. Da winkte fast wundersam ein Ruf an die Johannes-GutenbergUniversität in Mainz. Am I6. Dezember I946, fünf Tage nach der Einsetzung eines neuen Akademiedirektors, verließ er Berlin und nahm aus der Akademie, die nicht mehr die seine war, neben zwei Dienstsiegeln und diversen Akten auch ausreichend Kopfbögen und Umschläge der Preußischen Akademie der Wissenschaften mit nach Mainz, wo er sich in der Folgezeit als »noch im Amt befindlicher Direktor « gerierte.

In den kommenden Jahren organisierte er im Rücken der Akademie und ihres Präsidenten Stroux, den er I 949 immer »noch aufhängen « mochte, über Westberlin einen regen Transfer verschiedener wissenschaftlicher Materialien der DAW nach Mainz, wo diese sich zum Teil noch heute befinden. »Verlagerung « bürgerte sich als geläufiger Ausdruck für diesen Diebstahl ein.

Fritz Schwarz arbeitete inzwischen am 4. Faszikel des VIR (ira ff.). Seine Lage war zunächst besser als die von Scheel. Denn im Oktober I947 wurde er von der Entnazifizierungskommission für Juristen beim Berliner Magistrat als Mitläufer eingestuft, so dass er ab Dezember I947 einen bis Ende März I948 befristeten Werkvertrag erhielt - eine Viermonatsfrist, innerhalb der geprüft werden sollte, ob man seinen alten Wunsch nach einer festen Anstellung beim Vokabular erfüllen könne. Heinrich Mitteis, der inzwischen anstelle des verstorbenen Heymann in die VIR-Kommission gewählt worden war, befürwortete die Anstellung, so dass zum I. April I948 der Anstellungsvertrag hätte ausgestellt werden können.

Aber an diesem Tage verschwand Fritz Schwarz und fuhr nach Münster, wo ihm »durch die Vermittlung wohlgesinnter Freunde ... eine bezahlte Beschäftigung als wissenschaftlicher Mitarbeiter an der Universität « (Kaser) angeboten worden war. Max Kaser, der gütige Oberbuchhalter des von den Romanisten erfundenen römischen Rechts, gehörte zweifellos zu diesen Freunden, denn er hatte Stroux bereits durch den emeritierten Koschaker mitteilen lassen, dass er beabsichtige, das VIR in Münster weiter zu bearbeiten. Dazu brauchte er freilich das in Berlin befindliche Material. Schwarz nahm es umstandslos gleich mit - wenn auch nicht vollständig, sondern nur die Buchstaben » $\mathrm{I}$ und $\gg \mathrm{P}-\mathrm{Q}$ «, an denen er 
gearbeitet hatte, eine Kurzsichtigkeit, die Scheel, der auch an diesem Coup eifrig mitgewirkt hatte, I949 zu der ärgerlichen brieflichen Frage an Schwarz veranlasste: "Wie sollen wir nun das noch im Akademiegebäude befindliche (Material) herausbekommen? « Die Kommunisten hatten inzwischen offenbar das Aufpassen gelernt.

Dass die Dinge insgesamt rascher abgelaufen wären, wenn Schwarz eine umfänglichere "Verlagerung « vorgenommen und » $\mathrm{K}-\mathrm{M}$ « nicht in Berlin »vergessen « hätte, ist wenig wahrscheinlich. Zunächst habilitierte er sich an der Universität Münster bei Kaser, wo er im November 1950 die venia legendi für Römisches und Deutsches bürgerliches Recht erhielt. Für die Weiterarbeit am Buchstaben » $\mathrm{I}$, beginnend mit »ira « und endend mit »iuxta «, hatte der schon nicht mehr ganz junge Privatdozent wenig Zeit. Eine schwere Migräne, an der Schwarz ab 1952 zu leiden begann, behinderte seine Arbeit zusätzlich. »I« kam also nicht voran, obwohl sich unter den verlagerten Materialien sogar ein noch von Kübler gefertigtes und an Abraham übergebenes Manuskript mit den Wörtern »iste« bis »iuxta « befand.

I955 folgte Fritz Schwarz einem Ruf an die Universität Mainz. Kurz zuvor hatten Deutschland Ost und Deutschland West sich geeinigt, die Sachlage, wie sie nun einmal für das VIR war, zu akzeptieren und in Berlin die Buchstaben $» \mathrm{~K}-\mathrm{M}$ «, von Schwarz aber $» I$ « sowie $\gg \mathrm{P}-\mathrm{Q}$ « bearbeiten zu lassen.

In Mainz traf Schwarz wieder auf Helmuth Scheel, der erneut geworden war, was er immer sein wollte: Generalsekretär einer Akademie. Zwar nicht mehr der Preußischen, aber immerhin einer stark preußisch eingefärbten. Denn im Juli 1949 war in Worms unter seiner tatkräftigen Mitwirkung die in Mainz residierende »Akademie der Wissenschaften und der Literatur « gegründet worden, deren Gründungsmitglieder, zu denen er auch selbst gehörte, nahezu ausnahmslos ehemalige Mitglieder der Preußischen Akademie der Wissenschaften waren, darunter mehrheitlich solche, deren Namen nach I945 aus den Mitgliederlisten gestrichen worden waren - Namen, wie etwa Paul Diepgen, Carl August Emge, Franz Specht, Otmar Freiherr von Verschuer, bei deren Nennung dem zeithistorisch Informierten noch heute die Haare zu Berg stehen. Im ersten Jahrbuch (1950) dieser Gesellschaft erschien als Mitarbeiter der Kommission für Rechtswissenschaft der soeben habilitierte Dr. Schwarz. 
Fritz Schwarz blieb nur sechs Jahre in Mainz. I96I wechselte er und mit ihm die »westdeutschen « Teile des VIR an die Universität Marburg, von wo aus die Fachwelt I964, nach einer Pause von 25 Jahren wieder ein Faszikelchen erhielt. Es umfasste »ira « bis »ita «. »Ita« allerdings nur zur Hälfte. Mit dem Rest des Buch-

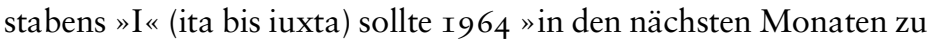
rechnen « sein.

Als Schwarz I970 emeritiert wurde, bat er in einem Brief, der nicht viel Wahres enthielt, Berlin um die Überlassung der Materialien von » $\mathrm{L}-\mathrm{M}$ «, da »der Schluß von $\gg \mathrm{K}$... zum größten Teil druckfertig « sei und er jetzt als Emeritus das Vokabular fertigstellen wolle. Ein Jahr vor ihrer dritten Namensänderung in der Nachkriegszeit (I972: »Akademie der Wissenschaften der DDR «) schickte die Akademie das Material leihweise nach Marburg, so dass I97I der gesamte noch unbearbeitete Rest des VIR sich wieder in einer Hand befand.

I974 starb Fritz Schwarz.

Der 5. Faszikel des 3. Bandes (ita - iuxta) erschien schließlich im Jahre I978. Seine Herausgeberin, Marianne Meinhart (I920I994), der auf Anregung und Betreiben von Max Kaser das Marburger VIR-Material nach Linz übersandt worden war, schrieb im knappen Vorwort: articulos huius fasciculi F. Schwarz composuerat. Was immer componi in diesem Zusammenhang heißen mochte - denn »komponiert « hatten an »ira « bis »iuxta « doch schon Abraham und Kübler - abgeschlossen war Buchstabe »I« jedenfalls beim Tode von Schwarz immer noch nicht. Denn: M. Meinhart articulos suscepit partim imperfectos.

Bereits fünf Jahre später (I983) kehrte das I97 I von Berlin an Schwarz ausgeliehene Material wieder dorthin zurück. Allerdings nur dieses. I987 erschien die letzte Lieferung des VIR.

VI.

Ein intensives Portrait des Vocabularium Iurisprudentiae Romanae als Typus eines besonders erfolgreichen Langzeitvorhabens deutscher Geisteswissenschaft verdiente vielleicht schärfere Konturen und mehr Farbe, als sie der vorliegende Text bieten kann. Dies würde die Anfügung weiterer Lebensläufe erfordern: etwa den von Theodor Mommsen, der den Umschwung einer anwendungsbestimmten Disziplin zu einer vergangenheitsorientierten gestaltend 
erlebt hat und dessen langer Schatten die Arbeit am Vocabularium bis zu ihrem Ende begleitete. Oder den des Geheimrates Ernst Heymann, der als Vorsitzender der Kommission für das VIR viele Jahre für Vieles verantwortlich war, was hier nicht zur Sprache kommen konnte. Auch Walter Erdmann, der seit 1939 bis zu seinem Schlaganfall und Tod im Jahre 1955 bescheiden, unauffällig und zuverlässig als Honorarkraft am Vocabularium mitwirkte, dürfte nicht übergangen werden.

Andererseits ist es wahrscheinlich unnötig, durch noch mehr Material, durch weitere Pointierung und Akzentuierung zu unterstreichen, wie die zitierten Lebensstränge sich berühren, überschneiden und wechselseitig dementieren. Um das Röcheln der Vergeblichkeit zu hören und um das Sinnvolle in der Sinnlosigkeit zu erkennen, muss das Wispern der Texte nicht lautstark überhöht werden. Es ist für willige Ohren vernehmlich genug. Denn wie sagt der Prediger: "Geschieht auch etwas, davon man sagen möchte: Siehe, das ist neu? Es ist zuvor auch geschehen in den langen Zeiten, die vor uns gewesen sind «.

Dieter Simon

\section{Nachweise und Danksagung}

Zahlreiche Hinweise, Aktenauszüge und instruktive Ausarbeitungen zur Geschichte und zum Nachkriegsschicksal des Vocabularium Iurisprudentiae Romanae verdanke ich dem Archivar der Berlin-Brandenburgischen Akademie der Wissenschaften, Herrn Dr. Wolfgang Knobloch, ohne dessen Unterstützung der Text noch weit größere Lücken aufweisen würde, als dies ohnehin der Fall ist.

Auf das erbarmungswürdige Schicksal von Paul Abraham bin ich durch die sorgfältige, umfassende und einfühlsame Studie von Jens Thiel aufmerksam geworden, der ich die hier verwendeten Fakten zu Abraham entnahm: Paul Abraham. Ein vergessener Mitarbeiter der Preußischen Akademie der Wissenschaften, in: Die Preußische Akademie der Wissenschaften zu Berlin, 19I4I945, hg. von Wolfram Fischer unter Mitarbeit von Rainer Hohlfeld und Peter Nötzoldt, Berlin 200I, 435-458. 
Die Urteile zum Lebenslauf des römischen Rechts in Deutschland stützen sich weithin auf das unüberholbare Meisterwerk von Franz Wieacker, Privatrechtsgeschichte der Neuzeit. Unter besonderer Berücksichtigung der deutschen Entwicklung, 2. Aufl. Göttingen 1967.

Aufschlussreich zur Funktion und Bedeutung der Neuübersetzung des Corpus Iuris sind die Darlegungen anlässlich der Vorstellung des I. Bandes der Übersetzung durch die Übersetzer und ihre Gäste in der Zeitschrift der Savigny-Stiftung für Rechtsgeschichte, Romanistische Abteilung, I08 (I99I) 700-730.

Einen sehr ergiebigen Nachruf auf B. Kübler hat LeOpOLD WENGER in der Zeitschrift der Savigny-Stiftung für Rechtsgeschichte, Romanistische Abteilung, 6I (I94I) IX-XLIV verfasst.

$\mathrm{Zu}$ der von den Experten nahezu mit Stillschweigen übergangenen Fertigstellung des Vokabulars siehe etwa die jenseits der Inhaltsbeschreibung kommentarlosen Hinweise von JoHannaMARIA FrösChL, in: Zeitschrift der Savigny-Stiftung für Rechtsgeschichte, Romanistische Abteilung, IO6 (I989) 756; JosePH MéLÈZe-ModrZEJEwski, in: Revue historique de droit français et étranger, 66 (I988) 268; WolfGang Waldstein, in: Anzeiger für die Altertumswissenschaften, 4I (I988) Sp. 91/92; F. B. J. Wubbe, in: Tijdschrift voor Rechtsgeschiedenis, 58 (I990) I 5 I-I 53.

Über den Themenkreis: Historisierung des Römischen Rechts, Rechtsgeschichte und Rechtsdogmatik, Römisches Recht als gemeineuropäisches Zukunftsrecht kann man sich anhand von Reinhard Zimmermann, Heutiges Recht, Römisches Recht und heutiges Römisches Recht, in: Rechtsgeschichte und Privatrechtsdogmatik, hg. von Reinhard Zimmermann in Verbindung mit Rolf KnÜtel und Jens Peter Meincke, Heidelberg I999, I-39 und EduARd Picker, Rechtsdogmatik und Rechtsgeschichte, in: Archiv für die civilistische Praxis 20I (200I) 763-859 umfassend informieren.

Einen Nachruf auf Fritz Schwarz, in dem die hier erzählten Fakten allerdings entweder fehlen oder verschleiert und ungenau berichtet sind, hat MAX KASER verfasst: Zeitschrift der SavignyStiftung für Rechtsgeschichte, Romanistische Abteilung 92 (I975) 492-496.

Über die Geschicke des VIR wurde in der Zeitschrift der Savigny-Stiftung für Rechtsgeschichte, Romanistische Abteilung, von Beginn an (Band 4, I883, I 25-I29) fortlaufend, wenngleich 
mit abnehmender Ausführlichkeit berichtet. Dort findet sich auch eine Würdigung der letzten Verantwortlichen Marianne Meinhart durch Peter Apathy (Band I I2, I995, 739-743).

Zur unmittelbaren Nachkriegsgeschichte der ehemaligen PreuBischen Akademie findet man ausgezeichnete Berichte in dem von Jürgen Kocka unter Mitarbeit von Peter Nötzoldt und Peter Th. Walter herausgegebenen Band: Die Berliner Akademien der Wissenschaften im geteilten Deutschland I945-I990, Berlin: Akademie Verlag 2002.

Die Daten zur Kriminalgeschichte von Helmuth Scheel und der Mainzer Akademie hat Wolfgang Knobloch minutiös rekonstruiert. Die insgesamt wenig raffinierten Anstrengungen, den wahren Sachverhalt zu verschleiern, sind leicht zu durchschauen, und die von Mainz nach Scheels Tod (1967) vor der Übergabe seiner Akten an das Geheime Staatsarchiv (I970) durchgeführte Reinigung ist, wie alle Aktensäuberungen in der Geschichte, nicht so vollständig erfolgt, dass sich nicht viele verräterische Fingerzeige erhalten hätten. 